\title{
Retraction Note: Monitoring method based on GIS for submarine cable fault data
}

\author{
Cheng Yanhui ${ }^{1}$
}

Published online: 6 December 2021

(c) Saudi Society for Geosciences 2021

Retraction Note: Arabian Journal of Geosciences (2021) 14: 490 https://doi.org/10.1007/s12517-021-06717-z

The Editor-in-Chief and the Publisher have retracted this article because the content of this article is nonsensical. The peer review process was not carried out in accordance with the Publisher's peer review policy. The author has not responded to correspondence regarding this retraction.

The online version of the original article can be found at https:// doi.org/10.1007/s12517-021-06717-z

$\triangle$ Cheng Yanhui

Chengyanhui1010@163.com

1 Weifang University of Science and Technology,

Shouguang 262700, China 